\title{
Relação entre a Expressão da MUC1 e os Estadiamentos TNM e Astler-Coller no Câncer Colorretal
}

\author{
Relation Between the Expression of MUC1 and TNM and Astler-Coller Staging \\ Systems in Colorectal Cancer
}

\author{
PAULAGABRIELA MELO MORAIS ${ }^{1}$; MANOELÁLVARO DE FREITAS LINS NETO²; ANTENOR TEXEIRALEAL ${ }^{3}$; \\ CLÁUDIOTORRES DE MIRANDA ${ }^{4}$; MATEUS DE PAULAALBUQUERQUE ${ }^{5}$
}

\begin{abstract}
${ }^{1}$ Doutoranda da Faculdade de Medicina da Universidade Federal de Alagoas (FAMED/UFAL), ${ }^{2}$ Professor Doutor da FAMED/UFAL e Chefe do Serviço de Coloproctologia do Hospital Universitário Prof. Alberto Antunes (HUPAA/UFAL), ${ }^{3}$ Médico Patologista da Santa Casa de Misericórdia de Maceió, ${ }^{4}$ Professor Doutor da FAMED/UFAL, ${ }^{5}$ Residente (R3) do Serviço de Coloproctologia do HUPAA/UFAL.
\end{abstract}

MORAIS PGM; LINS NETO AF; LEAL AT; MIRANDA CT; ALBUQUERQUE MP. Relação entre a Expressão da MUC1 e os Estadiamentos TNM e Astler-Coller no Câncer Colorretal. Rev bras Coloproct, 2008;28(2): 178-186.

RESUMO: A expressão de marcadores tumorais que se correlacionam com a agressividade dos cânceres vem sendo investigada com vigor. Tendo o câncer colorretal significativa incidência, biomarcadores que possam avaliá-lo quanto a esse aspecto, não são exceção nesta investigação. OBJETIVO: estabelecer a relação entre agressividade do câncer colorretal de acordo com os estadiamentos TNM e Astler-Coller e a expressão da Mucina1 (MUC1) em uma determinada amostra de tumores. METODOLOGIA: foram examinados 36 cânceres colorretais ressecados pelos coloproctologistas do Hospital Universitário da UFAL quanto à presença de uma reação imuno-histoquímica positiva para MUC1 em padrão citoplasmático. Em seguida, correlacionou-se esta com os estádios dos tumores. RESULTADOS: A imunoexpressão da MUC1 ocorreu em 50\% dos casos. Destes, 61\% estavam entre os estádios T3 e T4; 39\% entre N1 e N2; todos os casos do estudo eram M0; e 40\% encontravam-se entre os estádios C1 e C3 de Astler-Coller. Avaliada a positividade por cada estádio em separado, percebeu-se que estes aumentaram proporcionalmente, principalmente em relação aos estadios "N" e Astler-Coller. CONCLUSÃO: a ausência da reatividade imuno-histoquímica à MUC1 não excluiu a possibilidade de evolução para um estadio avançado. Porém, sua presença denota a evolução do câncer colorretal para estádios mais agressivos.

Descritores: Mucinas; Câncer Colorretal; Estadiamento do Câncer; Marcadores de Tumor; Imuno-histoquímica.

\section{INTRODUÇÃO}

Os marcadores tumorais, especialmente os moleculares, vêm sendo utilizados extensivamente com a finalidade de caracterizar os processos neoplásicos. Quando se emprega os termos marcadores moleculares ou biomarcadores, refere-se à avaliação de moléculas específicas nos tecidos quanto à presença de doença ou indução de alterações em tecidos normais ou danificados $^{1}$. Muitos grupos químicos representam esta categoria, inclusive antígenos, aminoácidos e ácidos nucléicos, enzimas, poliaminas, além de proteínas e lipídeos de membrana celular específicas. Os biomarcadores estão sendo usados recentemente como indicadores de estágio e grau de diferenciação tumoral, podendo também ser úteis para monitorar respostas ao tratamento e prever recidivas ${ }^{1}$.

Enquanto o sistema de estadiamento tumornódulo-metástase (TNM), desenvolvido pelo American Joint Commitee on Cancer (AJCC) e aprovado pela

$\overline{\text { Trabalho realiza }}$ do no Serviço de Coloproctologia do Hospital Universitário Prof. Alberto Antunes Faculdade de Medicina da Universidade Federal de Alagoas. Maceió, Alagoas - Brasil. 
International Union Against Cancer (UICC) ${ }^{2}$, tem sido comumente usado como o mais confiável preditor de prognóstico, este novo direcionamento de visão pode adicionar uma sensibilidade ainda maior a tal função por usar parâmetros moleculares adicionais ${ }^{3}$.

Sabe-se que o epitélio colônico e retal é recoberto e protegido por muco cuja maioria das glicoproteínas constituintes são as mucinas (MUC), proteínas de alto peso molecular ricas em carboidratos, sendo assim, altamente glicosiladas ${ }^{3,4,5,6}$. A mucina I (MUC1), além de ser secretada para constituir o muco, faz parte também da estrutura das células da parede do cólon e do reto, expressando alguns de seus fragmentos na superfície dessas células ${ }^{3,6,7,8,9}$. Mucinas ancoradas na membrana podem ter uma função adicional relacionada com a interação entre proteínas na superfície celular. Várias alterações podem ocorrer nestas glicoproteínas transmembrana durante a carcinogênese colorretal, sendo algumas responsáveis por implicações fisiopatológicas ${ }^{5,8}$. Mudanças na estrutura e distribuição das mucinas na célula epitelial são estimadas serem causas de malignização e progressão do tumor ao alterar o comportamento biológico das células cancerígenas ${ }^{5,10}$. Além disso, algumas mucinas vêm sendo associadas à imunossupressão tumoral $^{11}$.

As alterações estruturais e quantitativas ocorridas nestas moléculas se dão em nível de epítopos, que podem eventualmente ser considerados antígenos, sendo identificados por técnicas de imuno-histoquímica nas células de cânceres colorretais por induzirem resposta antígeno-específica quando se mostram fortemente expressos na estrutura celular de tais tumores, mostrando-se negativos em mucosa colorretal normal $^{8,9,12}$. Tal resposta imune pode também induzir a produção de anticorpos que podem ser detectados na circulação sendo úteis no diagnóstico precoce e análise imunológica da neoplasia ${ }^{13}$. Todavia, devido ao metabolismo bacteriano, não é possível encontrar a MUC1 em amostras de fezes, apesar destas estarem presentes no lúmen colônico assim como a glicoproteína ${ }^{8}$.

Os adenocarcinomas de cólon e reto, especificamente, têm sido definidos como tumores compostos por mucina em $50 \%$ ou mais dos casos relatados em estudos $^{1}$. Quando se relaciona a expressão da MUC1 e o estadiamento do câncer, essa glicoproteína é mais freqüentemente expressa em carcinomas de alto grau de estadiamento do que em câncer colorretal de baixo $\operatorname{grau}^{1,3,14,15,16}$. É relatada também sua relação com maior potencial de malignização de tais neoplasias ${ }^{1,17}$. Contudo sua expressão é quase nula em mucosa colônica normal e em pólipos e adenomas ${ }^{8,15}$. Considera-se também a hipótese de que, independentemente do grau histopatológico, a MUC1 seria uma importante preditora de potencial metastático e prognóstico ${ }^{1,5,9,15,16}$.

\section{OBJETIVOS}

O objetivo desse estudo foi estabelecer e identificar um marcador biológico que pudesse predizer a agressividade de um tumor encontrado em estágios mais precoces de evolução e a relação entre o grau de agressividade do câncer colorretal de acordo com os sistemas de estadiamento TNM e Astler-Coller ${ }^{18,19,20}$ e a expressão do marcador tumoral MUC1 em uma determinada amostra de pacientes portadores de tal neoplasia, tratados pelo Serviço de Coloproctologia do Hospital Universitário Prof. Alberto Antunes da Universidade Federal de Alagoas.

\section{MATERIAL E MÉTODO}

Foram analisados 36 tumores primários de pacientes com câncer colorretal incluídos no estudo aleatoriamente, independentemente de sexo, idade ou raça. As peças cirúrgicas foram obtidas através de ressecções terapêuticas realizadas no Hospital Universitário Prof. Alberto Antunes da Faculdade de Medicina da Universidade Federal de Alagoas (UFAL) entre os anos de 2004 e 2007.

As técnicas operatórias utilizadas foram individualizadas para cada paciente e incluíram Colectomias, Hemicolectomias, Retossigmoidectomias, Amputações Abdomino-Perineais e Laparotomias convencionais. As peças cirúrgicas retiradas passaram por todo o procedimento anátomo-patológico padrão, desde sua fixação em formaldeído a $10 \%$ até sua inclusão em blocos de parafina.

Foram escolhidos os blocos de parafina que continham a maior representatividade de tecido tumoral e as menores áreas de necrose de cada peça para serem então enviados ao patologista responsável pela imuno-histoquímica dos tecidos. Este desconhecia os laudos anátomo-patológicos dos casos apresentados, analisando-os, portanto, de forma "cega". Os laudos foram obtidos dos arquivos do Serviço de Anatomia Patológica do HUPAA. 
O protocolo para a reação de imunohistoquímica iniciou-se com a desparafinização dos cortes de 3ìm de espessura inclusos em lâminas previamente tratadas com 3-Aminopropyltriethoxy-Silano (A3648, Sigma, USA).

O material foi imerso em recipiente de pressão com solução tampão Anidro Cítrico $10 \mathrm{mM}$, pH 6,0 e lacrado até a pressurização total. Foi dada sequiência ao processo com a reação de bloqueio da Peroxidase Endógena com Peróxido de Hidrogênio a $3 \%\left(\mathrm{H}_{2} \mathrm{O}_{2} 10\right.$ volumes). Após essa reação, o material foi lavado em solução salina tamponada com fosfatos (PBS - Phosphate Buffered Saline 10mM, $\mathrm{pH} 7,4)$.

Finalmente as lâminas foram incubadas com o anticorpo primário liofilisado Anti-MUC1 Glicoproteína, Monoclonal de camundongo, Clone Ma695, Isotipo IgG1 (NCL-MUC-1, Novocastra, United Kingdom), na diluição de 1:100, em tampão PBS contendo Albumina Bovina a $1 \%$ (BSA, A9647, Sigma, USA) e Azida Sódica a $0,1 \%\left(\mathrm{NaN}_{3}\right)$ por 30 minutos a $37^{\circ} \mathrm{C}$ e por 18 horas a $4^{\circ} \mathrm{C}$ em câmara úmida.

As lâminas foram lavadas em tampão PBS para então serem incubadas com o anticorpo secundário, tendo sido usado o LSAB (Biotinylated antirabbit, anti-mouse and anti-goat Ig in PBS) do kit LSAB+System-HRP (Code K0690, DakoCytomation, Denmark).

Lavadas mais uma vez em tampão PBS, foram incubadas, sendo, neste momento, com o complexo Streptavidin-HRP (Streptavidin conjugated to horseradish in PBS) do mesmo kit LSAB+SystemHRP.

A lavagem com tampão PBS foi uma última vez utilizada precedendo a última incubação das lâminas em solução substrato contendo 3,3' Diaminobenzidina Tetrahidroclorido (DAB) $60 \mathrm{mg} \%$ (D5637, Sigma, USA), Dimetilsulfóxido (DMSO), Peróxido de Hidrogênio a $3 \%\left(\mathrm{H}_{2} \mathrm{O}_{2} 10\right.$ volumes) e PBS.

As lâminas foram contracoradas com Hematoxilina de Harris e a montagem feita em Entellan (1.07961, Merck, Germany) para finalmente serem analisadas.

A análise da reação imuno-histoquímica foi realizada por leitura das lâminas em microscópio óptico com aumento de até 400x. O critério adotado como positivo para fins de resultados foi o achado da glicoproteína MUC1 através da ligação com o anticorpo
Anti-MUC1 em padrão citoplasmático nas células do tecido tumoral pesquisado. Os casos negativos foram aqueles nos quais se verificou a ausência de tal padrão de expressão da mesma.

\section{Análise estatística}

Trata-se de um estudo para avaliação de um teste diagnóstico. Analisa-se a Mucina 1 (MUC1) enquanto marcador da agressividade do câncer colorretal, correlacionando sua presença com os estadiamentos TNM e Astler-Coller.

Para estudar a relação entre os critérios em estudo utilizou-se o teste do Qui Quadrado $\left(\dot{\div}^{2}\right)$ de Pearson para avaliar a associação entre MUC1 e os estadiamentos TNM e Astler-Coller.

\section{RESULTADOS}

\section{Perfil dos Pacientes}

Nos 36 pacientes incluídos no estudo, a média de idade entre estes foi de aproximadamente 60,25 anos, com variações na faixa etária entre 16 a 86 anos. Quanto ao sexo, 15 pacientes eram do sexo masculino $(41,67 \%)$ e 21 , do sexo feminino $(58,33 \%)$.

\section{Diagnósticos Histopatológicos}

A partir da análise dos laudos das biópsias das peças cirúrgicas pôde-se definir qualitativamente os casos estudados. Os diagnósticos histopatológicos dados pelo patologista eram, em todos os casos, de Adenocarcinomas.

Por questões didáticas, analisaram-se os 36 tumores, sob três aspectos diferentes, sendo estes o grau de diferenciação da neoplasia, a morfologia do tumor e a qualidade deste de ser mucossecretor ou não. (Tabela 1).

Uma curiosidade foi a observação de células em "anel de sinete" em 2 casos (5,56\%), impelindo uma investigação para o caso da lesão ser secundária a uma neoplasia gástrica primária.

\section{Estadiamentos TNM e Astler-Coller}

Tomando-se conhecimento dos mesmos laudos anátomo-patológicos foram realizadas avaliações dos estadiamentos TNM e Astler-Coller, previamente ao estudo imuno-histoquímico, para se definir o estadiamento dos tumores na amostra colhida. Os critérios do sistema TNM foram analisados separadamente. (Gráficos 1 e 2). 
Tabela 1 - Diagnósticos Histopatológicos.

\begin{tabular}{lcrc}
\hline Diagnósticos Histopatológicos & n & \% \\
\hline Adenocarcinoma & Tipo histológico & & \\
& Grau de diferenciação & 36 & $100,00 \%$ \\
Bem diferenciado & & 15 & $41,67 \%$ \\
Moderadamente diferenciado & & 15 & $41,67 \%$ \\
Mal diferenciado & Morfologia & 5 & $2,78 \%$ \\
Indefinido & & 5 & $13,89 \%$ \\
& & 13 & $13,89 \%$ \\
Vegetante ou Polipóide & & 13 & $36,11 \%$ \\
Ulceroso ou Infiltrativo & 5 & $36,11 \%$ \\
Úlcero-vegetante & & $5,89 \%$ \\
Anular ou Constrictivo & Mucossecreção & 13 & $36,11 \%$ \\
Presente & & 23 & $63,89 \%$ \\
Ausente ou Indefinida & & 23 \\
\hline
\end{tabular}

\section{Análise Imuno-histoquímica}

Após todo o protocolo da reação imunohistoquímica, as lâminas foram avaliadas por um patologista que desconhecia os resultados acima expostos. Este constatou, pela análise em microscópio óti-

\section{Estadiamento TNM}

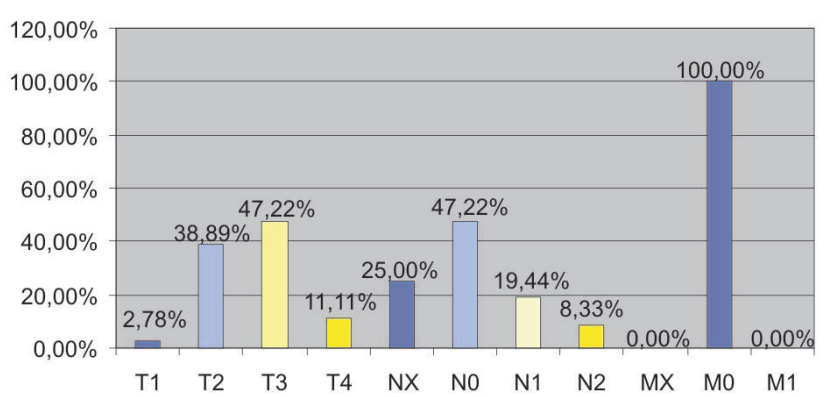

Gráfico 1 - Estadiamento TNM.

Estadiamento Astler-Coller

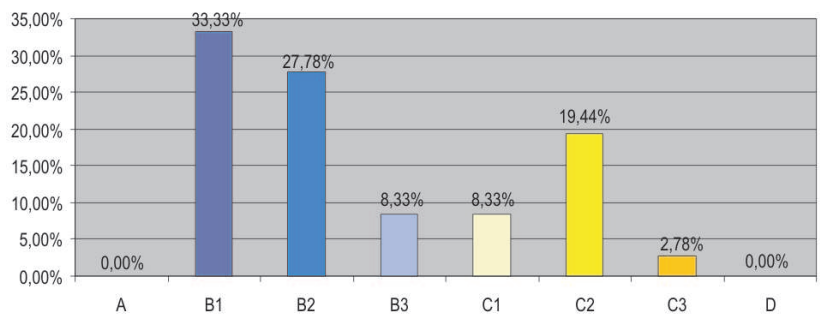

Gráfico 2 - Estadiamento Astler-Coller. co com aumento de até $400 x$, a presença da imunorreação da MUC1 com seu anticorpo, em padrão citoplasmático em 18 casos (50\%). A positividade foi considerada quando o citoplasma das células produtoras ou que continham a Mucina 1 corou-se em tom acastanhado, mesmo entremeando células que não produziam tal glicoproteína. Estas se mantiveram azuladas. (Figura 1). Casos em que a reação deu-se em padrão de membrana foram considerados negativos, assim como tecidos onde não ocorreu a reação em nenhum tipo de padrão, totalizando estes iguais 18 casos $(50 \%)$. Percebeu-se a negatividade ao encon-

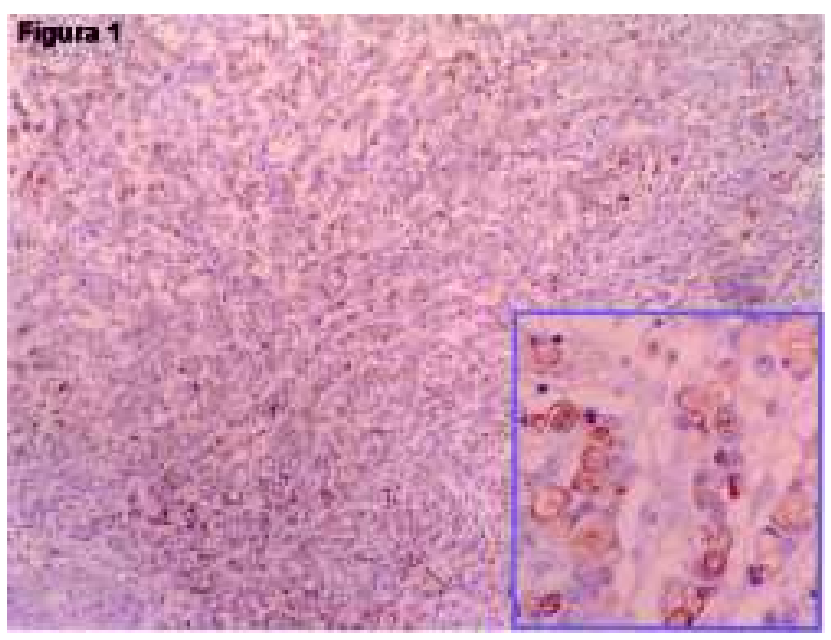

Figura 1 - Padrão positivo em adenocarcinoma pouco diferenciado com achados focais de mucossecreção. (T2NOMO, AC: B1). 
trar todas as células em tons de azul, não encontrando o tom acastanhado produzido pela reação de imunohistoquímica (Figura 2).

\section{Relação MUC1 versus Estadiamentos}

\section{TNM e Astler-Coller}

Após análise detalhada dos resultados das reações de imuno-histoquímica foi feita a correlação da positividade destas com os estadiamentos TNM e Astler-Coller. Primeiramente, foram levados em conta todos os 36 casos e analisada a porcentagem que cada estádio representava na positividade geral da Mucina 1. Em seqüência, foi avaliada a porcentagem de positividade em cada estádio separadamente.

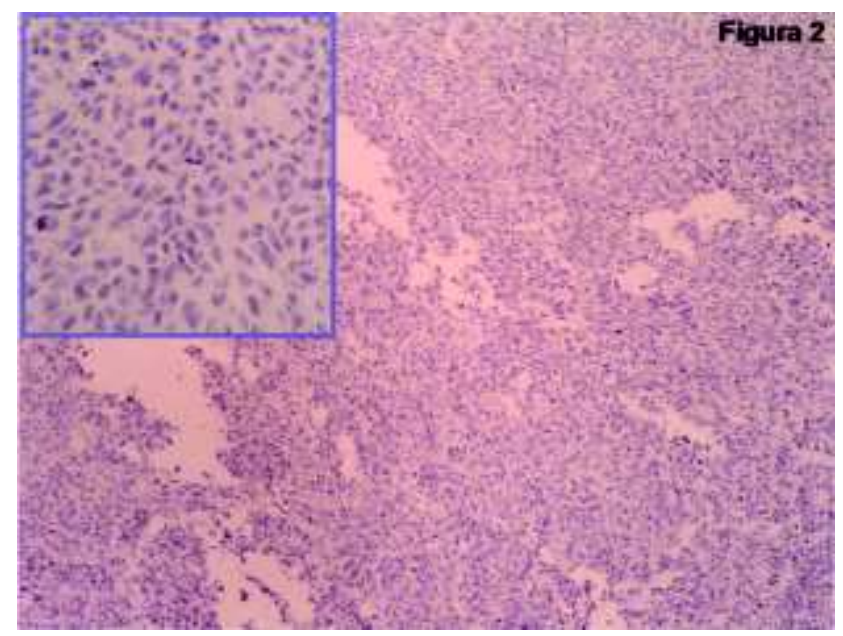

Figura 2 - Padrão negativo em adenocarcinoma bem diferenciado de sigmóide. (T2NOMO, AC: B1).
Com relação ao primeiro sistema, o TNM, este foi desmembrado em seus componentes para uma melhor didática de avaliação de resultados. Sabendose que "T" refere-se ao tumor primário, "N", ao comprometimento de linfonodos regionais e "M", às metástases à distância, obtivemos os resultados expostos na Tabela 2 .

Como todos os casos foram M0, não foi feito o cálculo para tal classificação.

Já em relação ao sistema Astler-Coller de estadiamento, os resultados obtidos foram os apresentados na Tabela 3 .

Dada sequiência à análise dos dados, verificouse a porcentagem de positividade da MUC1 em cada estádio separadamente. O sistema TNM de estadiamento foi, mais uma vez, desmembrado pelo mesmo motivo citado na análise geral dos casos positivos. Os resultados podem ser observados nos Gráfi$\cos 3$ e 4 .

\section{DISCUSSÃO}

A Mucina 1 (MUC1) é uma glicoproteína expressa em células de adenocarcinomas colorretais, e que dificilmente se encontra em mucosa colônica normal ou em tumores benignos do cólon. Existem relatos de que a MUC1 teria um papel importante no grau de malignização das neoplasias colorretais ${ }^{17}$.

Várias investigações estão sendo feitas a cerca dos mecanismos pelos quais a expressão da MUC1

Tabela 2 - Relação do estadiamento TNM e a presença da Mucina 1.

\begin{tabular}{lrrrc}
\hline TNM versus MUC1 & \multicolumn{2}{c}{ MUC1 NEGATIVO } & \multicolumn{2}{c}{ MUC1 POSITIVO } \\
\cline { 2 - 5 } & $\mathbf{n}$ & $\mathbf{\%}$ & $\mathbf{n}$ & $\mathbf{\%}$ \\
\hline T1 & 1 & $6 \%$ & 0 & $0 \%$ \\
T2 & 7 & $39 \%$ & 7 & $39 \%$ \\
T3 & 8 & $44 \%$ & 9 & $50 \%$ \\
T4 & 2 & $11 \%$ & 2 & $11 \%$ \\
& & & & $\mathbf{p}=\mathbf{0 , 7 9}$ \\
NX & 5 & $28 \%$ & 4 & $22 \%$ \\
N0 & 10 & $56 \%$ & 7 & $39 \%$ \\
N1 & 3 & $17 \%$ & 4 & $22 \%$ \\
N2 & 0 & $0 \%$ & 3 & $17 \%$ \\
& & & & $\mathbf{p}=\mathbf{0 , 2 9}$ \\
MX & 0 & $0 \%$ & 0 & $0 \%$ \\
M0 & 18 & $00 \%$ & 18 & $100 \%$ \\
M1 & 0 & & 0 & $0 \%$ \\
\hline
\end{tabular}


Tabela 3 - Relação do estadiamento Astler-Coller e a presença da Mucina 1.

\begin{tabular}{lcccc}
\hline ASTLER-COLLER versus MUC1 & \multicolumn{2}{c}{ MUC1 NEGATIVO } & \multicolumn{2}{c}{ MUC1 POSITIVO } \\
\cline { 2 - 5 } & $\mathbf{n}$ & $\mathbf{\%}$ & $\mathbf{n}$ & $\mathbf{\%}$ \\
\hline T1 & 1 & $6 \%$ & 0 & $0 \%$ \\
A & 0 & $0 \%$ & 0 & $0 \%$ \\
B1 & 6 & $33 \%$ & 6 & $33 \%$ \\
B2 & 7 & $39 \%$ & 4 & $22 \%$ \\
B3 & 2 & $11 \%$ & 1 & $6 \%$ \\
C1 & 1 & $6 \%$ & 1 & $6 \%$ \\
C2 & 2 & $0 \%$ & 5 & $28 \%$ \\
C3 & 0 & $0 \%$ & 1 & $6 \%$ \\
D & 0 & & 0 & $0 \%$ \\
& & & & $\mathrm{p}=0,63$ \\
\hline
\end{tabular}

TNM e MUC1

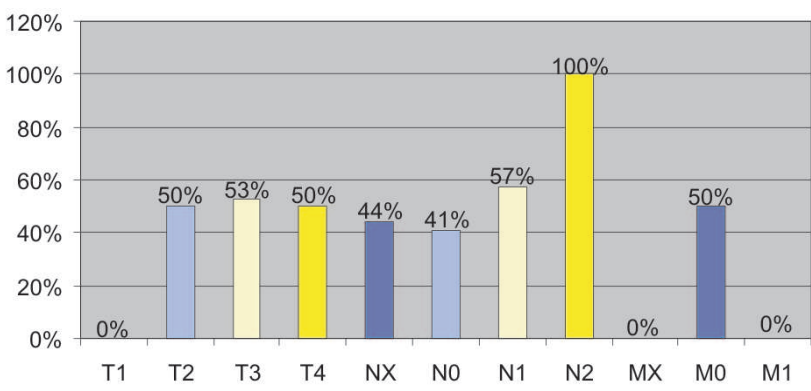

Gráfico 3 - Positividade da Mucina 1 por estádio TNM.

Astler-Coller e MUC1

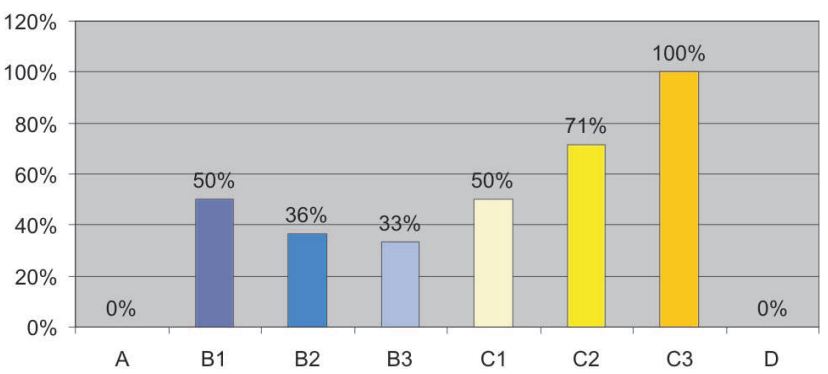

Gráfico 4-Positividade da Mucina 1 por estádio de Astler-Coller.

se relacionaria com a agressividade tumoral, medida por seu estadiamento, e o prognóstico do paciente, sabendo-se que o estadiamento é importante para determinar o grau de sobrevida do paciente. Existem também teorias sobre um possível aumento do potencial metastático do câncer independentemente de seu grau de diferenciação e estadiamento histopatológico ${ }^{1,5,9,15,16}$.
Para explicar esses mecanismos várias hipóteses foram aventadas. Tem-se dito que a MUC1 (i) funcionaria como uma molécula que inibiria a adesão entre as células, induzindo a liberação destas pelo tumor para outros sítios e para circulação ${ }^{22,23}$; (ii) agiria como inibidor da interação entre os linfócitos citotóxicos e as células tumorais ${ }^{24}$; (iii) teria papel na adesão celular à matriz extracelular mediada pela integrina ${ }^{25}$; e (iv) seria também supressora da resposta humoral pela células T induzindo assim uma imunossupressão ${ }^{26}$.

Analisando-se as reações imuno-histoquímicas quanto à expressão da Mucina 1 nos 36 casos de adenocarcinomas colorretais, foi demonstrado que a presença desta, tende a ter uma relação com um maior grau de agressividade dos tumores tendo como parâmetro sistemas TNM e Astler-Coller.

Nos tumores examinados, apesar da igualdade numérica entre casos negativos e positivos, a imunorreatividade da Mucina 1 manteve discreta relação com graus crescentes de estadiamento tanto pelo sistema TNM, como pelo Astler-Coller.

O padrão citoplasmático, que caracterizou a positividade dos casos, não foi detectado no estadiamento $\mathrm{T} 1$ da casuística, mas estava presente em carcinomas de estádio T2 e estádio T4. Dos 18 casos positivos, sete (39\%) encontravam-se em estádio T2, enquanto $11(61 \%)$ foram casos de tumores que ultrapassaram a muscular própria da parede, caracterizando os estádios T3 e T4, sendo atribuídos nove casos $(50 \%)$ a T3 e dois $(11 \%)$, a T4. Foram levados em consideração esses dados devido a maior parte da casuística encontrar-se nos estádios T2 (14/ 
$36,38,89 \%)$ e T3 (17/36, 47,22\%). Devido a esta discrepância, analisou-se também a reatividade da MUC1 dentro de cada estádio. O resultado obtido foi semelhante entre os casos positivos e negativos. Os tumores T2 e T4 tiveram resultados relativos iguais. Dos 14 casos de T2, obteve-se sete casos positivos (50\%). Enquanto que em quatro casos de T4, dois foram MUC1 positivos, totalizando iguais $50 \%$ de positividade. Porém entre os 17 casos classificados no estadiamento T3, observou-se discreta diferença de percentual, sendo nove tumores MUC1 positivos $(53 \%)$ e oito negativos $(47 \%)$.

Quanto à presença de linfonodos regionais acometidos $(\mathrm{N})$, a análise foi realizada agregando-se os estádios N1 e N2 por ambos caracterizarem a presença de comprometimento linfonodal diferindo apenas em sua quantidade. Dessa maneira, entre os 18 casos positivos, foi observada outra igualdade de porcentagens. Sete tumores (39\%) foram classificados no estádio N0 e outros sete (39\%) nos estádios N1 e $\mathrm{N} 2$, totalizados quatro casos $(22 \%) \mathrm{N} 1$ e três $(17 \%)$ $\mathrm{N} 2$. Os quatro restantes (22\%) foram classificados com NX. Dessa maneira não foi possível avaliar a relação entre a reatividade da MUC1 e estadiamento "N" em todos os 18 casos positivos, pois esses quatro casos NX, se avaliados, tanto poderiam ser estádios de comprometimento linfonodal (N1 ou N2), como de ausência de acometimento (N0). Todavia, ao se analisar os estádios individualmente, pôde-se verificar que tumores NX apresentaram uma positividade para MUC1 de 44\% (4/9). Contudo, à avaliação da porcentagem de Mucina 1 positiva nos estádios restantes, observou-se que esta aumentou proporcionalmente ao avanço destes. Foi observada positividade em $41 \%$ (7/17), $57 \%$ (4/7) e $100 \%$ (3/3) dos casos nos estádios N0, N1 e N2 respectivamente. Dessa maneira, pôde-se perceber que a MUC1 encontra-se imunorreativa nos estádios mais avançados de comprometimento linfonodal.

Em todos os 36 casos, não se identificou a presença de metástases, classificando todos os cânceres como M0. Assim não foi possível obter resultados mais significativos quanto a esse critério, sendo, obviamente, $100 \%$ dos casos de positividade estadiados como M0 e, de todos os casos M0, 50\% foram MUC1 reativos.

Analisados os resultados de acordo com o sistema Astler-Coller, estes foram conflitantes no que se refere à positividade geral, devido à predominân- cia de dois estádios em detrimento dos outros que esse sistema apresenta, além da ausência dos estádios A e D. Exatamente um terço dos 36 casos (12) foram B1 representando, 33\% (6) dos 18 casos positivos. A classificação B2 respondeu por 10 casos $(27,78 \%)$ dos 36 totais, sendo imunorreativos em quatro (22\%) dos 18 MUC1 positivos. Os estádios B3, C1 e C3 responderam, cada um, por $6 \%$ dos 18 casos de positividade, tendo todos respectivamente apenas um caso positivo. O estádio C2 respondeu por $28 \%$ (5 casos) dos casos de positividade. Esses resultados tiveram o perfil significativamente alterado quando se avaliou a porcentagem de positividade por estádio em separado. Dentre os tumores com estádio B1, a positividade alcançou metade dos casos, totalizando seis tumores MUC1 reativos. No estádio B2, a positividade estava diminuída em relação a B1. Apesar do número de casos absoluto apresentar uma pequena diferença, B2 obteve uma positividade de 4 casos em 11 (36\%). A imunorreatividade dos tumores com estádio B3 foi semelhante ao B2, porém deve-se levar em consideração o fato de que havia um número menor de casos com essa classificação. A positividade da Mucina 1 nos casos B3 foi de 33\% (1/3). De modo semelhante ao que aconteceu com a classificação "N", os estádios subseqüentes de Astler-Coller aumentaram sua imunorreatividade mesmo com um número pequeno de casos. Os tumores $\mathrm{C} 1$ tiveram uma Mucina 1 positiva em $50 \%$ dos casos (1/2). A positividade de C2 foi ainda maior e com uma quantidade absoluta de casos também significativamente maior, totalizando $71 \%$ (5/7). Já o único câncer classificado como C3 obteve uma reação imuno-histoquímica positiva para a MUC1.

Mesmo sendo um marcador biológico pouco explorado na atualidade, sendo utilizado apenas com fins de pesquisa, a Mucina 1 tem mostrado um certo grau de concordância entre sua expressão e a classificação dos cânceres colorretais mais agressivos.

Apesar deste estudo não ter apresentado uma boa significância estatística e um pequeno número de casos, diversos outros trabalhos, de conceituados centros de pesquisa, mostram uma estatística bastante favorável para tal associação. Estes, ao contrário, tinham a sua disposição uma amostra de tumores bem mais relevante, onde puderam analisar um leque maior de estadiamentos que eventualmente não apareceram em nosso estudo por causas diversas. 
O emprego desse marcador rotineiramente é uma prática pouco utilizada, principalmente aqui no Brasil, devido à pequena experiência em reações imuno-histoquímicas dos laboratórios e por este tipo de reação requerer uma maior experiência, além de ser muito dispendiosa, necessitando de serviços e profissionais que tenham a intenção de aprimorar e atualizar seu arsenal de opções diagnósticas.

Outro fato relevante é a pequena quantidade de trabalhos acerca do assunto, o que dificulta a pesquisa neste tópico. Este estudo é pioneiro na utilização da expressão da Mucina 1 em câncer colorretal no Brasil e em língua portuguesa, sendo, portanto, uma possível fonte de novas tendências científicas. Devido a pequena casuística é de fundamental importância outros projetos com este enfoque, para que se possa avaliar, comparar e aprimorar os resultados.

\section{CONCLUSÃO}

A ausência de reatividade imuno-histoquímica à Mucina 1 nas células tumorais não exclui a possibilidade dessa neoplasia evoluir para um estádio avançado. Porém, sua presença é sugestiva como marcador de evolução do câncer colorretal para estádios mais agressivos em acordo com os sistemas TNM e Astler-Coller.

\section{AGRADECIMENTOS}

Agradecimentos especiais a todos os funcionários dos serviços de Anatomia Patológica e Coloproctologia do Hospital Universitário Prof. Alberto Antunes - UFAL e do serviço de Anatomia Patológica da Santa Casa de Misericórdia de Maceió que tanto contribuíram para o êxito deste trabalho.

ABSTRACT: The expression of tumor markers that correlates with the aggressiveness of cancers has been strongly investigated. Having colorectal cancer a significant incidence, biomarkers that can evaluate it concerning this aspect are not an exception in this inquiry. AIM: To establish a relation between aggressiveness of colorectal cancer according to TNM and Astler-Coller staging systems and the expression of Mucin1 (MUC1) in a determined sample of tumors. METHODS: 36 colorectal cancers resected by proctologists of the University Hospital of UFAL were examined regarding the presence of positive immunohistochemical reaction for MUC1 in cytoplasmic patterns. After that, the positive cases and its stages were correlated. RESULTS: Immunoexpression of MUC1 occurred in 50\% of the cases. Among these, $61 \%$ were between stages T3 and T4; 39\% between N1 and N2; all cases of the study were M0; and $40 \%$ were classified between $\mathrm{C1}$ and $\mathrm{C} 3$ in Astler-Coller system. When evaluated MUC1 positivity in each stage separately, a proportional increase of both was perceived, mainly in stages " $N$ " and Astler-Coller. CONCLUSION: The absence of imunohistochemical reactivity to MUC1 did not exclude the possibility of evolution for an advanced staged tumor. However, its presence denotes evolution of colorectal cancer for more aggressive stages.

Key words: Mucins; Colorectal Cancer; Cancer Staging; Tumor Markers; Immunohistochemistry.

\section{REFERÊNCIAS}

1. Grizzle WE, Manne U, Jhala NC, Weiss HL. Molecular characterization of colorectal neoplasia in translational research. Arch Pathol Lab Med. 2001 Jan;125(1):91-8. Review.

2. Collaborative Staging Task Force of the American Joint Committee on Cancer. Collaborative Staging Manual and Coding Instructions, version 01.03.00. Jointly published by American Joint Committee on Cancer (Chicago, IL) and U.S. Department of Health and Human Services (Bethesda, MD), 2004. NIH Publication Number 04-5496. Incorporates updates through September 8, 2006.

3. Suzuki H, Shoda J, Kawamoto T, Shinozaki E, Miyahara N, Hotta $\mathrm{S}$ et al. Expression of MUC1 recognized by monoclonal antibody MY.1E12 is a useful biomarker for tumor aggressiveness of advanced colon carcinoma. Clin Exp Metastasis. 2004;21(4):321-9.
4. Ajioka Y, Allison LJ, Jass JR. Significance of MUC1 and MUC2 mucin expression in colorectal cancer. J Clin Pathol. 1996 July; 49(7): 560-564.

5. Hiraga Y, Tanaka S, Haruma K, Yoshihara M, Sumii K, Kajiyama G et al. Immunoreactive MUC1 expression at the deepest invasive portion correlates with prognosis of colorectal cancer. Oncology. 1998 Jul-Aug;55(4):307-19.

6. ByrdJC, BresalierRS. Mucins and mucin binding proteins in colorectal cancer. Cancer Metastasis Rev. 2004 Jan-Jun;23(1-2):77-99.

7. Biermer-Hüttmann AE, Walsh MD, McGuckin MA, Ajioka Y, Watanabe H, Leggett BA et al. Immunohistochemical staining patterns of MUC1, MUC2, MUC4, and MUC5AC mucins in hyperplastic polyps, serrated adenomas, and traditional adenomas of the colorectum. J Histochem Cytochem. 1999 Aug;47(8):1039-48.

8. Limburg PJ, Ahlquist DA, Gilbert JA, Harrington JJ, Klee GG, Roche PC. Immunodiscrimination of colorectal neoplasia 
using MUC1 antibodies: discrepant findings in tissue versus stool. Dig Dis Sci. 2000 Mar;45(3):494-9.

9. Baldus SE, Mönig SP, Huxel S, Landsberg S, Hanisch FG, Engelmann $\mathrm{K}$ et al. MUC1 and nuclear beta-catenin are coexpressed at the invasion front of colorectal carcinomas and are both correlated with tumor prognosis. Clin Cancer Res. 2004 Apr 15;10(8):2790-6.

10. Cao Y, Schlag PM, Karsten U. Immunodetection of epithelial mucin (MUC1, MUC3) and mucin-associated glycotopes (TF, $\mathrm{Tn}$, and sialosyl-Tn) in benign and malignant lesions of colonic epithelium: apolar localization corresponds to malignant transformation. Virchows Arch. 1997 Sep;431(3):159-66.

11. Kim JA, Dayton MA, Aldrich W, Triozzi PL. Modulation of CD4 cell cytokine production by colon cancer-associated mucin. Cancer Immunol Immunother. 1999 Dec;48(9):52532.

12. Koido S, Hara E, Torii A, Homma S, Toyama Y, Kawahara H et al. Induction of antigen-specific CD4- and CD8-mediated T-cell responses by fusions of autologous dendritic cells and metastatic colorectal cancer cells. Int J Cancer. 2005 Nov 20;117(4):587-95.

13. Nakamura H, Hinoda $Y$, Nakagawa N, Makiguchi $Y$, Itoh F, Endo $\mathrm{T}$ et al. Detection of circulating anti-MUC1 mucin core protein antibodies in patients with colorectal cancer. $\mathbf{J}$ Gastroenterol. 1998 Jun;33(3):354-61.

14. Tanimoto T, Tanaka S, Haruma K, Yoshihara M, Sumii K, Kajiyama G et al. MUC1 expression in intramucosal colorectal neoplasms. Possible involvement in histogenesis and progression. Oncology. 1999 Apr;56(3):223-31.

15. Matsuda K, Masaki T, Watanabe T, Kitayama J, Nagawa H, Muto T et al. Clinical significance of MUC1 and MUC2 mucin and p53 protein expression in colorectal carcinoma. Jpn J Clin Oncol. 2000 Feb;30(2):89-94.

16. Baldus SE, Mönig SP, Hanisch FG, Zirbes TK, Flucke U, Oelert $S$ et al. Comparative evaluation of the prognostic value of MUC1, MUC2, sialyl-Lewis(a) and sialyl-Lewis(x) antigens in colorectal adenocarcinoma. Histopathology. 2002 May;40(5):440-9.

17. Li A, Goto M, Horinouchi M, Tanaka S, Imai K, Kim YS et al. Expression of MUC1 and MUC2 mucins and relationship with cell proliferative activity in human colorectal neoplasia. Pathol Int. 2001 Nov;51(11):853-60.

18. Astler VB, Coller FA. The prognostic significance of direct extension of carcinoma of the colon and rectum. Ann Surg. $1954 ; 139: 846-852$
19. Way LW, Doherty GM. Cirurgia: Diagnóstico \& Tratamento. $11^{\mathrm{a}}$ ed. Rio de Janeiro: Guanabara Koogan, 2004.

20. Towsend CM, Beauchamp RD, Evers BM, Mattox KL. Sabiston, Tratado de Cirurgia: a base biológica da moderna prática cirúrgica. Rio de Janeiro: Elsevier, 2005.

21. Landis JR, Koch GG. The measurement of observer agreement for categorical data. Biometrics 1977; 33:159-74

22. Ligtenberg MJL, Buijs F, Vos HL, Hilkens J. Suppression of cellular aggregation by high level episialin. Cancer Res. 1992; 52: 2318-2324.

23. Makiguchi Y, Hinoda Y, Imai K. Effect of MUC1 mucin and anti-adhesion molecule on tumor cell growth. Jpn J Cancer Res. 1996; 87:505-511.

24. Van de Wiel-Van Kemeade E, Lightenberg MJL, de Boer AJ et al. Episialin (MUC1) inhibits cytotoxic lymphocyte-target cell interection. J Immunol. 1993; 151: 767-776.

25. Wesseling J, Van Der Valk SW, Vos HL, Sonnenberg A, Hilkens J. Episialin (MUC1) over-expression inhibits intregrinmediated cell adhesion to extracellular matrix components. $\mathrm{J}$ Cell Biol. 1995; 129: 255-265.

26. Agrawal B, Krants MJ, Reddish M, Longenecked BM. Cancerassociated MUC1mucin inhibits human T-cell proliferation, which is reversible by IL-2. Nat Med. 1998; 4: 43-49.

27. Rossi BM, Pinho M. Genética e biologia molecular para o cirurgião. São Paulo: Lemar, 1999.

28. Manne U, Weiss HL, Grizzle WE. Racial differences in the prognostic usefulness of MUC1 and MUC2 in colorectal adenocarcinomas. Clin Cancer Res. 2000 Oct;6(10):4017-25.

29. Ishizu H, Kumagai J, Eishi Y, Takizawa T, Koike M. Mucin core protein expression by colorectal mucinous carcinomas with or without mucus hyperplasia. J Gastroenterol. 2004;39(2):125-32.

30. Dittmann J, Keller-Matschke K, Weinschenk T, Kratt T, Heck T, Becker HD et al. CD8+ T-cell response against MUC1derived peptides in gastrointestinal cancer survivors. Cancer Immunol Immunother. 2005 Aug;54(8):750-8. Epub 2004 Dec 22.

Endereço para correspondência:

PAULA GABRIELA MELO MORAIS

R. Cláudio Ramos, 523/702, Ponta Verde, Maceió - AL

CEP: 57035-020

E-mail:paula_morais@hotmail.com 